\title{
obituary
}

\section{Leland J. Haworth}

DR Leland J. HAWORTH, prominent physicist, administrator and government official, died on 5 March 1979, in Port Jefferson, New York, at the age of 74. A former director of the Brookhaven National Laboratory, commissioner of the United States Atomic Energy Commission, and director of the United States National Science Foundation, he brought to those organisations a wealth of experience as a teacher, a research scientist, a project leader and a science administrator.

His activities were not restricted to science development in the U.S. only. A strong advocate of international cooperation in science, he played an active role in fostering such cooperation.

Leland Haworth first became involved with 'big science' when he was engaged in major microwave radar research and development programmes at the Massachusetts Institute of Technology's Radiation Laboratory from 1941 to 1946. His responsibilities grew from those of a components development engineer to those of head of the Receiver Components Division and a member of the laboratory's steering committee. His specialty was electronics, especially in data presentation and precision instrumentation.

Following a brief return to the University of Illinois as professor of physics, Haworth in 1947 joined the Brookhaven National Laboratory (BNL) as assistant director in charge of special projects. Brookhaven was established in 1946 by the United States Government and Associated Universities, Inc. (AUI) as a multidisciplinary research institution, a primary purpose of which was to provide special facilities essential for basic research in nuclear and related sciences.

Haworth was appointed director of Brookhaven in 1948. He stimulated the development of a truly user-oriented philosophy of service to the scientific community, including the development and provision of ever more advanced facilities. In the early 1950s the Cosmotron (a $3.0 \mathrm{GeV}$ proton accelerator) and the graphite research reactor were brought into service. The $30 \mathrm{GeV}$ alternating gradient synchrotron (AGS) was authorised in 1954, brought into operation in 1960, and today remains one of the key elements in the United States high energy physics programme. Similarly, under his

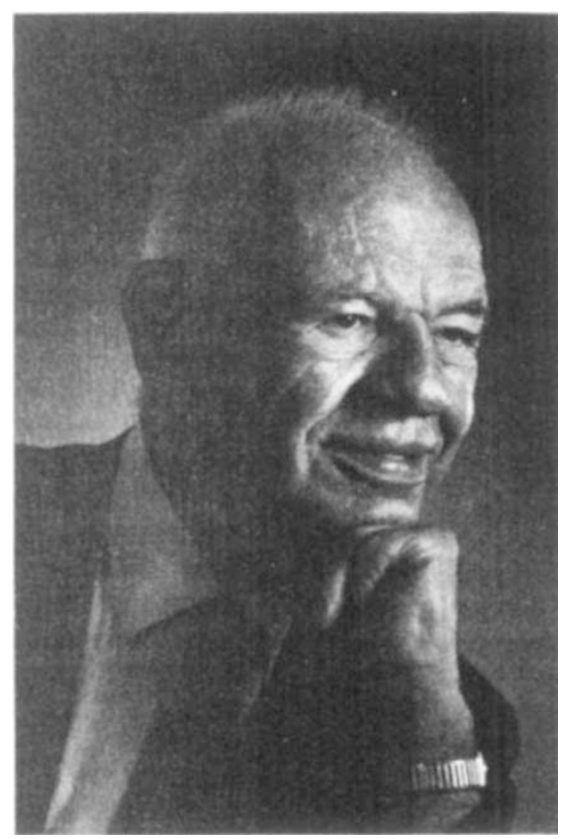

direction, construction of the high flux beam reactor $(40 \mathrm{MW})$ was initiated in 1959, and today it is still the major U.S. research reactor providing external high intensity beams of neutrons for research in physics, chemistry and biology.

Haworth's position as director of Brookhaven and his personal interest in high energy accelerator development were of great benefit to CERN both in the initial planning and development of that institution and in bringing the alternating gradient focusing concept, through CERN and BNL joint studies, to a reality in the Brookhaven AGS and the CERN proton synchrotron. This close cooperation between the two institutions has continued.

From 1951 to 1960, Haworth also served as vice president of Associated Universities, Inc. $\mathrm{He}$ was named president in 1960 and held that post, while continuing as laboratory director, until the spring of 1961 .

Leland Haworth immersed himself completely in every activity he undertook. His drive, his insistence on facts and accuracy, his pursuit of excellence and his clarity of expression were hallmarks. If Haworth did it, it was done well. It might have taken longer but it was done correctly. His leadership and, above all, his consideration for staff and regard for their capabilities and achievements earned the respect and admiration of all of his associates.

Haworth's influence extended beyond Brookhaven: his services were in demand as a member of numerous study groups and advisory panels-for the White House, the Department of Defense and other U.S. Government Agencies.

In 1961, President John F. Kennedy appointed Haworth commissioner of the U.S. Atomic Energy Commission. $\mathrm{He}$ rapidly became involved in matters of national security, civilian energy development and the support of fundamental research. As a commissioner, he was heavily involved in the nuclear weapons development programme and in the preparation of the 1962 AEC Report to the President on civilian nuclear power.

Haworth recognised the urgent need for restraint in nuclear weapons development, especially in the test programmes then carried out primarily in the atmosphere. $\mathrm{He}$ advocated a test ban that could be readily monitored by national means, an approach that led to the limited test ban treaty prohibiting testing in the atmosphere and under water.

The Atomic Energy Commission's 1962 Report to the President on civilian nuclear power was a masterpiece of its time. It was a major governmental energy planning document and, though its thrust was nuclear, reference was made to the need for conservation and to the development of coal resources. Haworth's analytical approach, rigorous logical presentations and other contributions to the study gave it substance and credibility and set the tone for what is now a necessary ingredient of all energy planning.

President Kennedy asked Haworth to leave the Atomic Energy Commission in order to become director of the National Science Foundation; he assumed office on 1 July, 1963. During Haworth's six-year term, he brought the foundation to maturity in a period that saw great expansion of federal support for the conduct of basic science. He guided the development of a programme which increased the number of high-quality institutions across the nation, and he pioneered NSF efforts to link fundamental science to applied science and technology.

Haworth returned to AUI in 1969 as special assistant to the president. He continued as a consultant to the president and to the BNL director following his retirement in 1977.

Leland John Haworth was born in Michigan on 11 July 1904. He grew 
up in Indiana and attended Indiana University, receiving his AB in 1925 and $A M$ in 1926, both in physics. In addition to his academic pursuits, he participated in varsity baseball and tennis. He received his $\mathrm{PhD}$ in physics from the University of Wisconsin in 1931.

He was an instructor in physics at the University of Wisconsin from 1930 to 1937. During his graduate work and until 1934, he did research in solid state physics, specialising in the surface structure of metals. In 1934 he switched to nuclear physics, which thereafter remained his principal field.

Following one year as a Lalor Fellow in physical chemistry at the Massachusetts Institute of Technology, Haworth, in 1938, joined the physics department of the University of Illinois. His association with Illinois continued until 1947 except for five years of war-time leave at MIT.

Dr Haworth was a member of the board of directors of Oak Ridge Associated Universities (ORAU) from 1959 to 1961, and again from 1971 to February 1978, when he was elected director emeritus-the first time ORAU had made such an appointment.

$\mathrm{He}$ was a member of the National Academy of Sciences, the American Philosophical Society, Phi Beta Kappa and Sigma Xi. He was a fellow of the American Physical Society, the New York Academy of Sciences, the American Academy of Arts and Sciences, and the American Nuclear Society (member of board of directors, 1955-60; president, 1957-58).

For his work during World War II, Haworth received the President's Certificate of Merit. A mesa in the Antarctic and an asteroid have been named in his honour. He was the recipient of many honorary degrees.

The name of Haworth is synonymous with meticulous care for the work at hand. His traits of objectivity, attention to detail and sensitivity to the problems of others influenced all who worked wath him, and we are the better for it. The institutions with which he worked have been left with a Haworth heritage, and they are the better for it.

Gerald F. Tape

\section{W. R. Aykroyd}

Dr Wallace Ruddel.l. Aykroyd, CBE, who died on 7 February 1979, aged 79, was a nutritionist of international reknown since the early days of his career. His ability for meticulous work and great clarity of thought were soon recognised and his powers of organisation and administration left their mark in the many posts of distinction he held, particularly as the first Director of the Nutrition Division of the Food and Agriculture Organisation of the United
Nations from 1946 until 1960. His capacity to marshal facts and produce scientific reports in stylish and fluent prose made his publications important and influential in the fields of nutrition, public health and agriculture.

Graduating in medicine at Trinity College, Dublin, in 1924, where he was awarded the Vice-Chancellor's prize in English prose, he was appointed House Surgeon at the General Hospital, St John's, Newfoundland. He became interested in the deficiency diseases of the poorer fishermen and published an article on vitamin A deficiency in 1928 and a comprehensive report, 'Beriberi and other Deficiency Diseases in Newfoundland and Labrador', in the Journal of Hygiene in 1930. This 30page report illustrates well the qualities which were to become the hallmark of his work-a broad approach, clear presentation of facts and a deep compassion for the unfortunate victims of malnutrition. He recognised that the diseases found were not due to deficiencies of single nutrients but multiple deficiencies due to poverty and a monotonous winter diet. His findings were used, and confirmed, by a team, which included B. S. Platt and W. H. Sebrell, conducting a medical survey of nutrition in Newfoundland some fifteen years later.

After his appointment to the Health Organisation of the League of Nations in 1931 he pursued his research into the link between malnutrition and poverty at a time of international recession and severe unemployment. His report, Diet in Relation to Small Incomes, published by the League of Nations in 1933, included a scholarly discussion on adequate dietary standards and satisfactory nutrition at low cost and his critical appraisal and distrust for the high protein allowances recommended was well in advance of his time and makes salutary reading today. The report is a valuable historical record of the time, containing studies of working class diet and expenditure on food in Germany, England and the USA.

The Health Organisation of the League of Nations decided, in 1934, that a general report on nutrition was needed after some ten years of studies of nutrition in the field of public health. Dr Aykroyd and Dr Etienne Burnet were asked to undertake this by making a series of enquiries in different countries and to report on nutritional status, research and policies. Their publication, Nutrition and Public Health, printed by the League of Nations in 1935, was an important statement of the current nutrition situation and was used extensively by international committees in public health and agriculture as well as the International Labour Office. Following this report the Health Organisa- tion set up a Technical Commission for the Study of Nutrition which convened meetings of groups of experts who then produced reports (a procedure continued by FAO and WHO). The first report, The Physiological Bases of Nutrition (1936), relied heavily on the findings of the Aykroyd and Burnet report.

Following his appointment as Director of the Nutrition Research Laboratories in Coonoor, India, in 1935, Dr Aykroyd continued his work as an expert for the Technical Commission including research on the effect on nutrients of the milling of cereals and the influence of climate on food requirements. His work in India greatly enhanced the reputation of nutrition research in that country and the world famous Indian National Institute of Nutrition at Hyderabad was the result of his efforts. To this day, revised editions of The Nutritive Value of Indian Foods and the Planning of Satisfactory Diets retains his name as principal author in recognition of his original concepts for the work.

During his period at FAO from 1946 Dr Aykroyd's leadership gave the Nutrition Division a fine start and the reports of the Expert Committees (some jointly with WHO), which owed a lot to his guidance and editing, are consulted throughout the world. After his retirement from FAO, in 1960, he joined Professor B. S. Platt at the Department of Human Nutrition, London School of Hygiene and Tropical Medicine, where, as Senior Lecturer, he helped to set up regular courses which led to the present MSc in Human Nutrition, attended by graduates from all over the world. He wrote several books at this time including Food for Man and The Conquest of Deficiency Diseases which explained nutritional problems in terms understandable and interesting for the untrained reader. During his work as co-author of the FAO Studies, Legumes in Human Nutrition and Wheat in Human Nutrition he was able to indulge in his love of history as well as use his powers of marshalling a mass of facts into lucid and readable prose.

This interest in history, which had led to the writing in 1935 of Three Philosophers, one of whom had been his great hero, Lavoisier, was also evident in his book Sweet Malefactor: Sugar, Slavery and Society.

During his active retirement he carried on with nutrition consultancy work for WHO and OXFAM and found time to write The Conquest of Famine. A fitting tribute was made when this received the first award of a joint book award scheme of the British, Swedish and American Nutrition Foundations.

Joyce Doughty 